\title{
CULTURA DA SOJA EM SUCESSÃO AO CULTIVO DE MILHO EM CONSÓRCIO COM BRAQUIÁRIAS
}

\author{
Rodolfo de Niro Gazola ${ }^{*}$, Luiz Malcolm Mano de Melo ${ }^{2}$, Raíssa Pereira Dinalli ${ }^{1}$, Marcelo \\ Carvalho Minhoto Teixeira Filho ${ }^{3}$, Thiago de Souza Celestrino ${ }^{1}$ \\ ${ }^{1}$ Pós-graduando(a) em Agronomia - Universidade Estadual Paulista (UNESP), Faculdade de Engenharia, \\ Câmpus de Ilha Solteira, SP. *Email: rngazola@gmail.com \\ ${ }^{2}$ Professor Titular do Departamento de Fitossanidade, Engenharia Rural e Solos - Universidade Estadual \\ Paulista (UNESP), Faculdade de Engenharia, Câmpus de Ilha Solteira, SP. \\ ${ }^{3}$ Professor Doutor do Departamento de Fitossanidade, Engenharia Rural e Solos - Universidade Estadual \\ Paulista (UNESP), Faculdade de Engenharia, Câmpus de Ilha Solteira, SP.
}

RESUMO: A produção de palha no plantio direto deve ser suficiente para manutenção e sustentabilidade do sistema. O consórcio de milho com forrageiras como cultura antecessora da soja de verão constitui uma alternativa para suprir o aporte anual de palha necessário para manutenção. Sendo assim, o objetivo foi avaliar a cultura da soja implantada sobre palhada oriunda do consórcio de milho outonal com braquiárias em diferentes profundidades de semeadura, com ênfase para a produtividade de soja. O experimento foi conduzido, em 2009/10, na Fazenda de Ensino, Pesquisa e Extensão (FEPE), Selvíria/MS, da Faculdade de Engenharia de Ilha Solteira (FEIS/UNESP), em um LATOSSOLO VERMELHO Distroférrico, textura argilosa. O delineamento experimental foi em blocos ao acaso, em esquema fatorial $3 \times 3$, com quatro repetições. Os tratamentos constituíram na semeadura da soja sobre palhada do consórcio de milho com duas espécies de braquiárias (Urochloa brizantha cv. Marandú e Urochloa ruziziensis), cujas sementes foram misturadas ao fertilizante do milho e um tratamento testemunha (milho exclusivo) e três profundidades de deposição do fertilizante com sementes dessas forrageiras $(8 \mathrm{~cm}, 10 \mathrm{~cm}$ e $16 \mathrm{~cm})$. A produção total de palha foi maior nos consórcios e nas menores profundidades de semeadura das forrageiras. No cultivo da soja a população final e produção de matéria de seca de palha foram maiores sobre a palha proveniente das menores profundidades e a produtividade de grãos não foi significativamente influenciada pela palha dos consórcios e tão pouco pelas profundidades de deposição de adubo e sementes das forrageiras.

Palavras-chave: Glycine $\max$ L. Mecanização. Plantio direto. Produtividade de grãos.

\section{SOYBEAN CULTURE IN SUCCESSION TO THE CULTIVATION OF CORN INTERCROPPED WITH BRACHIARIA}

\begin{abstract}
The straw production in the no-tillage should be sufficient for maintenance and sustainability of the system. The intercrop of corn with forages as cultivated before the summer soybean sowing is an alternative to supply the annual intake of straw, which is important for maintenance and sustainability of tillage. Thus, the objective was to evaluate the soybean sowed over straw coming from the intercropping corn with autumnal
\end{abstract}


brachiarias at different depths of sowing, with emphasis on soybean yield. The experiment was conducted in 2009/10, at Experimental Station of UNESP Ilha Solteira/SP, in a clayey Oxisol. The statistical design was a randomized blocks constituted by 9 treatments and 4 replications. The treatments constituted in soybean sowing on straw of corn intercrop with two Brachiaria species (Urochloa brizantha cv. Marandú and Urochloa ruziziensis), which seeds were mixed with fertilizer to corn crop besides a control (without intercropping) and three depths $(8 \mathrm{~cm}, 10 \mathrm{~cm}$ and $16 \mathrm{~cm}$ ) of fertilizer deposition with seed of these forages (in the consortium and the control). Final population and dry mass production of soybean were higher on the straw from the lower depths of forages sowing. The grain yield of soybean was not significantly influenced by straw of consortium as well as by depths of fertilizer deposition and seeds of forage.

Key words: Glycine max L. Mechanization. No-tillage. Grain yield.

\section{INTRODUÇÃO}

A decomposição dos resíduos culturais do milho é mais lenta quando comparados aos da soja, em decorrência da sua mais alta relação $\mathrm{C} / \mathrm{N}$, maior heterogeneidade e quantidade de resíduos (FERNANDEZ et al., 2008).

Uma das premissas básicas para o Sistema Plantio Direto (SPD) está na obtenção de palha em quantidade e qualidade suficiente para manter o solo coberto durante o maior período possível do ano que, segundo Mello (2001), para regiões tropicais, o aporte deve ser de aproximadamente 10 toneladas por hectare/ano. Para isso é necessário o cultivo de espécies que, além de fornecerem grande quantidade de matéria seca de palha apresentem alta relação $\mathrm{C} / \mathrm{N}$, diminuindo a velocidade de decomposição da palha e protegendo por mais tempo o solo contra erosão e ação da radiação solar (PANTANO, 2003). O consórcio de milho outonal com forrageiras, como cultura antecessora da semeadura da soja de verão, constitui uma alternativa para suprir o aporte anual de palha nas regiões em que se pratica o cultivo de milho safrinha.

Segundo Chioderoli (2010), na consorciação de milho com braquiária para produção de grãos no outono e de soja no verão e se o foco secundário for formação de palha, é recomendada à utilização da Urochloa ruzizienses. O cultivo de soja sobre a palhada dos capins aumenta a produtividade em 11 sacas ha ${ }^{-1}$, em média, quando comparado a soja produzida sobre palhada somente de milho (COSTA et al., 2010). O milho safrinha em consórcio com braquiárias é uma tecnologia que permite manter a produtividade de grãos de milho safrinha e aumentar a produção de palha como forma de viabilizar o Sistema Plantio Direto na sucessão soja milho safrinha (BROCH; CECCON, 2007). A soja semeada sobre palhada do consórcio milho safrinha + Urochloa brizantha cv. Marandu apresenta produtividade significativamente superior aquela observada no cultivo sobre palhada de milho exclusivo, com incremento de 7,3 sc ha' (BROCH; RANNO, 2007).

Cultura Agronômica, Ilha Solteira, v.26, n.3, p.225-236, 2017 
Diante do exposto, o objetivo foi avaliar a cultura da soja implantada sobre palhada oriunda do consórcio de milho com braquiárias semeadas em diferentes profundidades de semeadura, com ênfase para a produtividade de soja.

\section{MATERIAL E MÉTODOS}

O experimento foi conduzido, em 2009/10, na Fazenda de Ensino, Pesquisa e Extensão (FEPE), Selvíria/MS, da Faculdade de Engenharia de Ilha Solteira (FEIS/UNESP), situada aproximadamente nas coordenadas geográficas $51^{\circ} 22^{\prime} \mathrm{W}$ e $20^{\circ} 22^{\prime} \mathrm{S}$, com altitude local de 350 metros com $4 \%$ de declividade e boa drenagem. A classificação climática da região de acordo com Köppen é Aw, definido como tropical úmido com estação chuvosa no verão e seca no inverno. O solo da área experimental foi classificado como LATOSSOLO VERMELHO Distroférrico, textura argilosa (EMBRAPA, 2013). A precipitação média anual é de $1370 \mathrm{~mm}$, a temperatura média anual é de $23,5^{\circ} \mathrm{C}$ e a umidade relativa do ar entre 70 a $80 \%$ (média anual). Na Figura 1 encontram-se os dados de precipitação pluvial, as temperaturas máximas, mínimas e as médias durante o desenvolvimento do experimento, registrados na Estação Meteorológica da Fazenda Experimental da UNESP. O fornecimento de água foi realizado pelo sistema de irrigação Pivô Central, com uma lâmina de água de aproximadamente $14 \mathrm{~mm}$ e turno de rega de 3 dias, seguindo o manejo de rotina da fazenda.

Utilizou-se o delineamento em blocos ao acaso, em esquema fatorial $3 \times 3$, com quatro repetições. As parcelas experimentais foram constituídas por sete linhas de soja, espaçadas entre si por $0,45 \mathrm{~m}$, com 20,0 m de comprimento e área útil correspondente a 3 linhas centrais de 5,0 m cada. Os tratamentos constituíram na semeadura da soja sobre palha das culturas antecessoras, cujos tratamentos foram: duas espécies de braquiárias (Urochloa brizantha cv. Marandú e Urochloa ruziziensis), cujas sementes foram misturadas ao fertilizante do milho e um tratamento testemunha (milho exclusivo) e três profundidades de deposição do fertilizante com sementes dessas forrageiras $(8 \mathrm{~cm}, 10 \mathrm{~cm}$ e $16 \mathrm{~cm})$.

A semeadura da cultura do milho em consórcio com braquiária foi realizada em 15/05/2009 em Sistema Plantio Direto (SPD), em área previamente dessecada com aplicação glifosato $\left(2,160 \mathrm{~kg}^{\text {i.a. }} \mathrm{ha}^{-1}\right)$ em área total. O híbrido simples utilizado foi o DKB $390 \mathrm{Y}$, de ciclo precoce visando uma população de 60 mil plantas ha $^{-1}$, com espaçamento entre linhas de $0,45 \mathrm{~m}$, densidade de semeadura de 2,7 sementes $\mathrm{m}^{-1}$ e tendo-se adotado 5 $\mathrm{cm}$ de profundidade de deposição da semente de milho. As sementes de milho foram tratadas com o produto tiodicarbe (600 g i.a. $100 \mathrm{~kg}^{-1}$ semente). A densidade de semeadura da braquiária foi de $8 \mathrm{~kg} \mathrm{ha}^{-1}$ de sementes certificadas de Urochloa brizantha cv. Marandú e Urochloa ruzizienses com valor cultural de $76 \%$, independentemente da forma de onsorciação, e as sementes foram misturadas ao adubo e acondicionadas no compartimento de fertilizante da semeadora, distribuídas à profundidade de $8 \mathrm{~cm}, 10 \mathrm{~cm}$ e $16 \mathrm{~cm}$, localizada abaixo da semente de milho. As regulagens das profundidades foram efetuadas pela pressão do conjunto de molas concêntricas responsáveis pela profundidade de deposição do adubo.

Cultura Agronômica, Ilha Solteira, v.26, n.3, p.225-236, 2017 

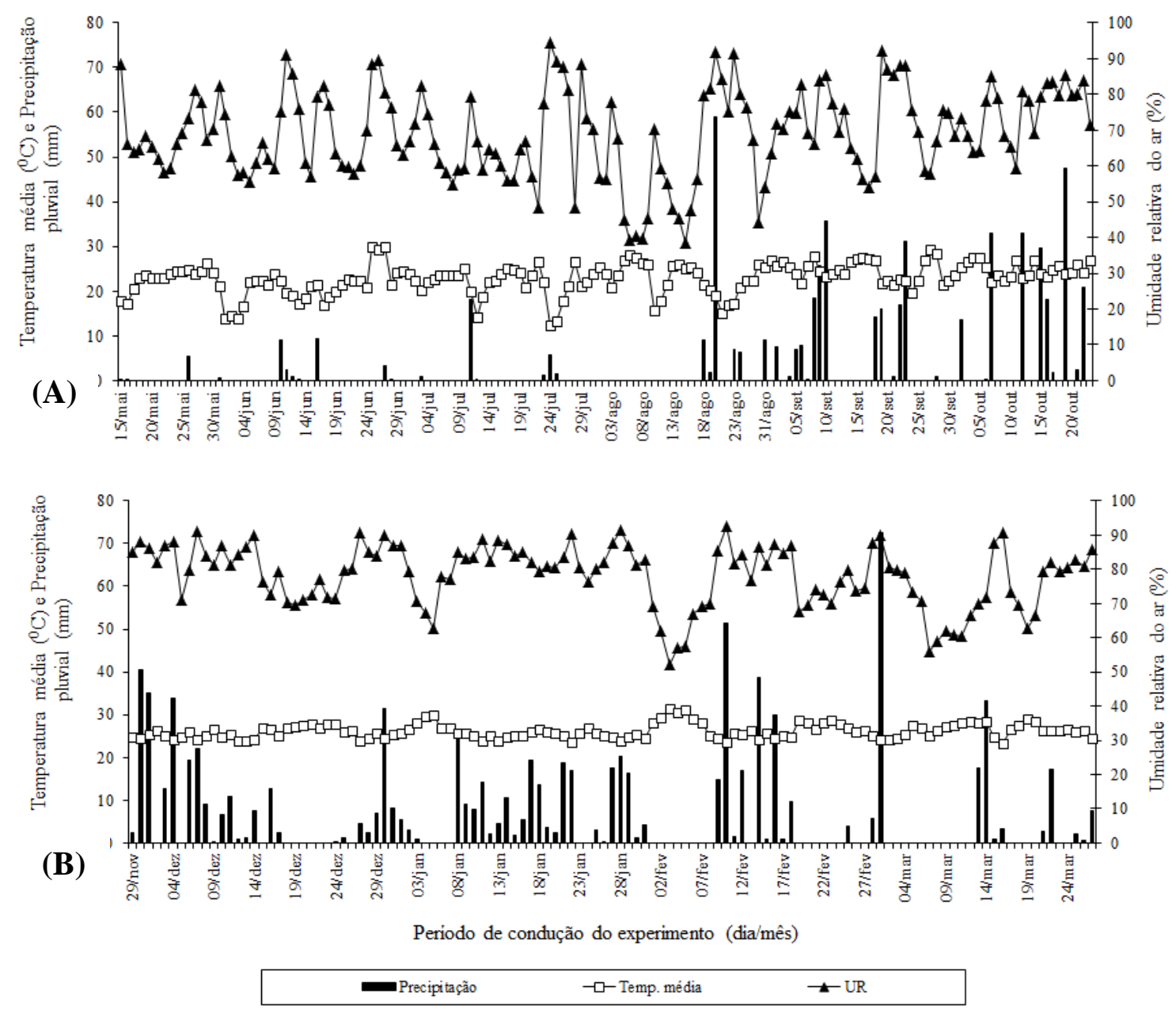

Figura 1. Precipitação pluvial $(\mathrm{mm})$, temperatura média $\left({ }^{0} \mathrm{C}\right)$ e umidade relativa do ar $(\%)$ durante a condução dos experimentos com milho consorciado com braquiárias (A) e cultura da soja em sucessão (B). Selvíria - MS, 2009 (A) e 2009/10 (B).

A semeadora utilizada foi da marca Marchesan, modelo Suprema com distribuição pneumática de sementes, configurada com mecanismo sulcador do tipo haste para deposição do adubo, sulcador de discos duplos para deposição de sementes e roda compactadora côncava, tracionada por trator de $77,23 \mathrm{~kW}$ de potência nominal.

Dois dias após a semeadura do milho foi realizada uma aplicação do herbicida dessecante de contato paraquat ( 240 g i.a. ha ${ }^{-1}$ ), com volume de aplicação de $200 \mathrm{~L} \mathrm{ha}^{-1}$, com a finalidade de eliminar as plântulas que emergiram após a dessecação.

As características químicas do solo determinadas antes da instalação do experimento (2009), segundo metodologia proposta por Raij et al. (2001) apresentaram os seguintes resultados: $15 \mathrm{mg} \mathrm{dm}^{-3}$ de P (resina); $20 \mathrm{~g} \mathrm{dm}^{-3}$ de M.O.; 4,8 de $\mathrm{pH}\left(\mathrm{CaCl}_{2}\right) ; \mathrm{K}, \mathrm{Ca}, \mathrm{Mg}$, $\mathrm{H}+\mathrm{Al}=2,2 ; 12,0 ; 7,0$ e $16,0 \mathrm{mmol}_{\mathrm{c}} \mathrm{dm}^{-3}$, respectivamente e $57 \%$ de saturação por bases. A adubação mineral de semeadura foi realizada com base nas características químicas do solo, sendo aplicados $24 \mathrm{~kg} \mathrm{ha}^{-1}$ de N, $84 \mathrm{~kg} \mathrm{ha}^{-1}$ de $_{2} \mathrm{O}_{5}$ e $48 \mathrm{~kg} \mathrm{ha}^{-1}$ de $\mathrm{K}_{2} \mathrm{O}$, correspondente a $300 \mathrm{~kg} \mathrm{ha}^{-1} \mathrm{da}$ fórmula comercial 08-28-16. 
A adubação de cobertura foi realizada quando as plantas de milho estavam no estádio V4, utilizando-se $60 \mathrm{~kg} \mathrm{ha}^{-1}$ de $\mathrm{K}_{2} \mathrm{O}$ e $120 \mathrm{~kg} \mathrm{ha}^{-1}$ de $\mathrm{N}$. Antes da adubação de cobertura foi aplicada atrazina (1000 g do i.a. ha ${ }^{-1}$.), herbicida de ação latifolicida. As colheitas do milho e das braquiárias foram realizadas no dia 23/10/2009. A matéria verde de braquiária foi por meio da coleta de $2 \mathrm{~m}$ de três linhas da área útil da parcela. Para avaliação da matéria seca da palhada do milho foram pesadas todas as plantas coletadas em $5 \mathrm{~m}$ de três fileiras da área útil da parcela. Após a trilha descontou-se o peso dos grãos obtendo-se assim o peso da matéria verde da palha. As amostras foram submetidas à secagem em estufa com circulação forçada de ar, por $72 \mathrm{~h}$ a $65^{\circ} \mathrm{C}$, determinando-se a $\%$ de umidade e posterior cálculo da produção de matéria seca de palha por hectare. No dia 13/11/2009 as braquiárias foram dessecadas com o herbicida glifosato $\left(2,160 \mathrm{~kg}\right.$ i.a. ha $\left.{ }^{-1}\right)$ para semeadura da soja.

A semeadura da cultura da soja foi realizada em 29/11/2009 sobre a palhada das braquiárias, sendo utilizada a cultivar MSOY 7908 RR, com poder germinativo de $80 \%$ e pureza 98\%. A densidade de semeadura foi de 15 sementes $\mathrm{m}^{-1}$, com espaçamento entrelinha de 0,45m, com uma população aproximada de 334 mil plantas ha ${ }^{-1}$. As sementes foram tratadas com carboxina (100 g i.a. $100 \mathrm{~kg}^{-1}$ semente) + fipronil $\left(50 \mathrm{~g}\right.$ i.a. $100 \mathrm{~kg}^{-1}$ semente) e $60 \mathrm{ml}$ de inoculante líquido de marca comercial Nitragin $\left(1,0 \times 10^{9}\right.$ células $\left.\mathrm{g}^{-1}\right)$. No décimo quinto dia (13/12/2009) após a semeadura foi realizado uma aplicação de glifosato (720 g i.a. ha ${ }^{-1}$ ) em área total, para eliminação das plantas daninhas remanescentes.

$\mathrm{Na}$ adubação mineral de semeadura foram aplicados $250 \mathrm{~kg} \mathrm{ha}^{-1}$ da formula comercial (02-20-20). Para o controle de lagartas e percevejos foi efetuado uma aplicação do inseticida Lambda-cyhalothrin (15 g i.a. ha $\left.{ }^{-1}\right)$. Para controle da ferrugem foi efetuado uma aplicação de epoxiconazol $\left(25\right.$ g i.a. ha $\left.{ }^{-1}\right)+$ piraclostrobina $\left(66,5\right.$ g i.a. ha $\left.{ }^{-1}\right)$. A colheita da soja foi realizada no dia 27/03/2010.

As avaliações realizadas na cultura da soja foram: a) altura de planta, determinada pela medição, com régua graduada em centímetros, da distância entre o colo da planta até a extremidade apical; b) altura de inserção da primeira vagem, sendo adotada a distância entre o colo da planta e a inserção da primeira vagem. Foram tomadas medidas de 10 plantas da área útil da parcela, na época da colheita; c) número de vagens por planta, tendo sido avaliado nas mesmas plantas anteriores. d) população final, sendo contadas as plantas na área útil de cada parcela. Os valores encontrados foram extrapolados para número de plantas $\mathrm{ha}^{-1}$; e) matéria seca de palha de soja, sendo pesadas todas as plantas da área útil da parcela, após a trilha descontou-se o peso dos grãos obtendo-se assim o peso da matéria verde da palha. A amostra foi submetida à secagem em estufa com circulação forçada de ar, por $72 \mathrm{~h}$ a $65^{\circ} \mathrm{C}$, determinando-se a \% de umidade e posterior cálculo da produção de matéria seca de palha por hectare. Após a trilha mecânica das plantas colhidas da área útil de cada parcela, foram determinadas, a (f) massa de cem grãos e a (g) produtividade de grãos soja. Os grãos foram separados, pesados e os valores corrigidos para a base úmida de $13 \%$ e os valores corrigidos para produtividade em $\mathrm{kg} \mathrm{ha}^{-1}$.

Cultura Agronômica, Ilha Solteira, v.26, n.3, p.225-236, 2017 
Os dados foram submetidos à análise de variância e as médias dos tratamentos foram comparadas pelo teste de Tukey a $5 \%$ de probabilidade. Para análise estatística foi utilizado o programa SISVAR (FERREIRA, 2008).

\section{RESULTADOS E DISCUSSÃO}

As menores profundidades de deposição das sementes das forrageiras apresentaram maior produtividade de matéria seca (Tabela 1) ao contrário da maior profundidade que apresentou menor produção em decorrência da emergência menor e mais lenta das espécies forrageiras, resultando em menor densidade de plantas, conseqüentemente reduzindo a produção de fitomassa da braquiária e aumentando leve sensivelmente a produção de palha do milho. Segundo Mota (2008) para Urochloa brizantha e Urochloa decumbens, as semeaduras mais profundas resultam em menor densidade de plantas. O mesmo foi verificado por Pacheco et al. (2010), que relataram que em semeadura a maiores profundidades pode prejudicar o estande de plantas. De acordo com Rezende et al. (2007), as maiores porcentagens de germinação ocorreram com as sementes de $U$. decumbens e $U$. brizantha, nas profundidades de 2,5 e 5,0 cm, para $U$. decumbens, a menor porcentagem foi verificada na profundidade de $15,0 \mathrm{~cm}$.

Para os sistemas de cultivo constatou-se que não houve diferença entre a produtividade de biomassa das espécies forrageiras (Tabela 1). Chioderoli et al. (2010), verificaram para mesma região e solo deste trabalho que o consórcio de milho outonal com diferentes espécies forrageiras (U. brizantha, $U$. decumbens e $U$. ruzizienses) não resultou em produtividades diferentes, com produtividade media em torno de $2500 \mathrm{~kg} \mathrm{ha}^{-1}$. De acordo com Pariz et al. (2011), produtividades de matéria seca de forrageiras em consorcio com milho acima de $2500 \mathrm{~kg} \mathrm{ha}^{-1}$ são satisfatórias. No presente trabalho, as produtividades de matéria seca estão próximas à idealizada por esses autores.

Segundo Amado (2000) e Mello (2001), o aporte anual de palha deve ser da ordem de 10 a $12 \mathrm{t} \mathrm{ha}^{-1}$. No presente trabalho, a quantidade acumulada de matéria seca de palha total referentes aos tratamentos das profundidades de semeadura de 8 e $10 \mathrm{~cm}$ (respectivamente de $10778 \mathrm{~kg} \mathrm{ha}^{-1}$ e $11444 \mathrm{~kg} \mathrm{ha}^{-1}$ ), independente da espécie forrageira, foram suficiente para suprir a quantidade de palha que deve ser adicionada anualmente à superfície do solo para manutenção e sustentabilidade do sistema plantio direto. Com relação às espécies forrageiras, independente das profundidades de semeadura, as quantidades de palha total no consórcio de milho com $U$. brizantha e $U$. ruziziensis (respectivamente de $11224 \mathrm{~kg} \mathrm{ha}^{-1} \mathrm{e}$ $10982 \mathrm{~kg} \mathrm{ha}^{-1}$ ), supriram o aporte anual de palha relatado pelo autor acima citado.

De acordo com Trecenti (2005), a U. ruziziensis vem sendo recomendada para sistemas de integração lavoura pecuária, principalmente por proporcionar rápida cobertura do solo, ter alta composição bromatológica, excelente reciclagem de nutrientes, facilidades na sua dessecação e produção uniforme de sementes. Quanto a $U$. brizantha, ressalta-se que 
embora esta forrageira seja afetada no sistema de consórcio, sua recuperação é rápida após a colheita do milho (PORTES et al., 2000), assim como ocorre com a U. ruziziensis.

Tabela 1. Valores de F, coeficientes de variação e valores médios de matéria seca de braquiárias, de milho e total de palha no sistema de consorciação de braquiárias (Urochloa brizantha cv. Marandú e Urochloa ruziziensis) com milho outonal, submetidas a três profundidades de deposição de semente misturada ao fertilizante do milho em plantio direto. (Selvíria/MS, 2009)

\begin{tabular}{|c|c|c|c|}
\hline & $\begin{array}{l}\text { Matéria seca de } \\
\text { braquiária } \\
\left(\mathrm{kg} \mathrm{ha}^{-1}\right)\end{array}$ & $\begin{array}{l}\text { Matéria seca de } \\
\text { milho } \\
\left(\mathrm{kg} \mathrm{ha}^{-1}\right)\end{array}$ & $\begin{array}{l}\text { Matéria seca total } \\
\text { de palha } \\
\left(\mathrm{kg} \mathrm{ha}^{-1}\right)\end{array}$ \\
\hline \multirow{3}{*}{$\begin{array}{l}\text { Sistemas de } \\
\text { cultivo } \\
\text { (S) }\end{array}$} & ME & 9177 a & $9177 \mathrm{~b}$ \\
\hline & $2461 \mathrm{a}$ & $8763 \mathrm{a}$ & $11224 \mathrm{a}$ \\
\hline & $2082 \mathrm{a}$ & 8900 a & $10982 \mathrm{ab}$ \\
\hline D.M.S. (5\%) & 826 & 1629 & 2022 \\
\hline \multirow{3}{*}{$\begin{array}{l}\text { Profundidades } \\
\text { de semeadura } \\
\text { (P) }\end{array}$} & $3326 \mathrm{a}$ & $8560 \mathrm{a}$ & $10778 \mathrm{ab}$ \\
\hline & $2813 \mathrm{a}$ & 9569 a & $11444 \mathrm{a}$ \\
\hline & $16 \mathrm{~cm}$ & $8711 \mathrm{a}$ & $9162 \mathrm{~b}$ \\
\hline \multirow[t]{2}{*}{ D.M.S. (5\%) } & 1238 & 1629 & 2022 \\
\hline & $1,059^{\mathrm{ns}}$ & $0,209^{\mathrm{ns}}$ & $3,822 *$ \\
\hline \multirow[t]{2}{*}{ Valor de F } & $19,383 * *$ & $1,392^{\mathrm{ns}}$ & $4,204 *$ \\
\hline & $0,503^{\mathrm{ns}}$ & $0,668^{\mathrm{ns}}$ & $1,864^{\mathrm{ns}}$ \\
\hline C.V. (\%) & 39,75 & 17,85 & 18,95 \\
\hline Média Geral & 2272 & 8947 & 10461 \\
\hline \multicolumn{4}{|c|}{$\begin{array}{l}\text { **significativo } \mathrm{p}<0,01 \quad \text { *significativo } 0,01<\mathrm{p}<0,05 \quad \text { ns: não significativo } \\
\text { Médias seguidas de mesma letra na coluna não diferem pelo teste de Tukey, a } 5 \% \text { de probabilidade. } \\
\mathrm{ME}=\text { Milho Exclusivo, } \mathrm{MUb}=\text { Milho + U.brizantha } \mathrm{e} \mathrm{MUr}=\text { Milho }+ \text { U.ruziziensis }\end{array}$} \\
\hline \multicolumn{4}{|c|}{$\begin{array}{l}\text { Com relação à altura de planta, altura de inserção de primeira vagem, número de } \\
\text { ns por planta e massa de cem grãos de soja (Tabela } 2 \text { ), verifica-se que não houve efeito } \\
\text { ificativo dos sistemas de cultivo, da profundidade de semeadura e nem interações } \\
\text { ificativas entre eles. Chioderoli (2010) verificou que para mesma região e solo deste } \\
\text { alho que palhada obtida pelo consórcio de milho outonal com diferentes espécies } \\
\text { ageiras ( } U \text {. brizantha, U. decumbens e } U \text {. ruzizienses) não influenciaram nas } \\
\text { cterísticas agronômicas avaliadas (altura de planta, altura de inserção de primeira } \\
\text { m, número de vagens por planta). Costa et al. (2015) avaliaram a produtividade da soja } \\
\text { e palhada de forrageiras (Sorghum bicolor L. Moench, Pennisetum glaucum L. R. Br. e } \\
\text { chloa brizantha cv. Xaraés) semeadas em diferentes épocas, constataram que não houve } \\
\text { ença para características agronômicas avaliadas (altura de inserção da primeira vagem, } \\
\text { ero de grãos por planta, número de vagens por planta, número de grãos por vagem, } \\
\text { ade final de plantas, massa de cem grãos). }\end{array}$} \\
\hline
\end{tabular}

Cultura Agronômica, Ilha Solteira, v.26, n.3, p.225-236, 2017 
Tabela 2. Valores de F, coeficientes de variação e valores médios de altura de planta, altura de inserção de primeira vagem, número de vagens por planta e massa de cem grãos de soja sobre palha de milho outonal consorciado com duas espécies de forrageiras semeadas em diferentes profundidades. (Selvíria/MS, 2009/10).

\begin{tabular}{|c|c|c|c|c|c|}
\hline & & $\begin{array}{l}\text { Altura de } \\
\text { planta } \\
\text { (cm) }\end{array}$ & $\begin{array}{c}\text { Altura de } \\
\text { inserção } 1^{\mathrm{a}} \text { vagem } \\
(\mathrm{cm})\end{array}$ & $\begin{array}{l}\text { Número de } \\
\text { vagens } \\
\text { por planta }\end{array}$ & $\begin{array}{c}\text { Massa de } \\
\text { cem grãos } \\
\text { (g) }\end{array}$ \\
\hline \multirow{3}{*}{$\begin{array}{l}\text { Sistemas de } \\
\text { cultivo } \\
\text { (S) }\end{array}$} & ME & $77,89 \mathrm{a}$ & $22,83 \mathrm{a}$ & $56,50 \mathrm{a}$ & $16,77 \mathrm{a}$ \\
\hline & MUb & 80,79 a & $22,14 \mathrm{a}$ & $62,68 \mathrm{a}$ & $17,53 \mathrm{a}$ \\
\hline & MUr & $77,57 \mathrm{a}$ & $21,33 \mathrm{a}$ & $66,47 \mathrm{a}$ & $17,66 \mathrm{a}$ \\
\hline \multirow{3}{*}{$\begin{array}{l}\text { Profundidades } \\
\text { de semeadura } \\
(P)\end{array}$} & $8 \mathrm{~cm}$ & $78,47 \mathrm{a}$ & $22,88 \mathrm{a}$ & $57,21 \mathrm{a}$ & $17,70 \mathrm{a}$ \\
\hline & $10 \mathrm{~cm}$ & $78,53 \mathrm{a}$ & $21,78 \mathrm{a}$ & $64,90 \mathrm{a}$ & $17,18 \mathrm{a}$ \\
\hline & $16 \mathrm{~cm}$ & $79,25 \mathrm{a}$ & $21,65 \mathrm{a}$ & $63,54 \mathrm{a}$ & $17,08 \mathrm{a}$ \\
\hline \multirow{3}{*}{ Valor de F } & $\mathbf{F}$ & $0,984^{\mathrm{ns}}$ & $1,173^{\mathrm{ns}}$ & $1,918^{\mathrm{ns}}$ & $0,629^{\mathrm{ns}}$ \\
\hline & $\mathbf{P}$ & $0,059^{\mathrm{ns}}$ & $0,940^{\mathrm{ns}}$ & $1,277^{\mathrm{ns}}$ & $0,310^{\mathrm{ns}}$ \\
\hline & $\mathbf{F} \times \mathbf{P}$ & $1,451^{\mathrm{ns}}$ & $0,607^{\mathrm{ns}}$ & $0,176^{\mathrm{ns}}$ & $0,420^{\mathrm{ns}}$ \\
\hline \multicolumn{2}{|l|}{ D.M.S. (5\%) } & 6,33 & 2,45 & 12,84 & 2,21 \\
\hline \multicolumn{2}{|l|}{ C.V. (\%) } & 7,88 & 10,88 & 20,34 & 12,01 \\
\hline \multicolumn{2}{|l|}{ Média Geral } & 78,75 & 22,10 & 61,88 & 17,32 \\
\hline
\end{tabular}

Garcia (2012), avaliando o desempenho da soja em SPD sobre as palhadas de milho de verão + forrageiras do gênero Urochloa, após a adubação nitrogenada, também não constatou efeito da palhada sobre essas avaliações da cultura da soja. Entretanto, ressalta-se que os valores médios obtidos no presente trabalho, para altura de planta e altura de inserção da primeira vagem, são superiores aos limites mínimos ideais para colheita mecânica, o qual segundo Mello (1988) é de $13 \mathrm{~cm}$, para inserção da primeira vagem, e, de acordo com Bonetti (1983), deve ser superior a $65 \mathrm{~cm}$ para altura de planta.

A população final e matéria seca de palha de soja foram significativamente influenciadas pelas diferentes profundidades de deposição de adubo e sementes das forrageiras (Tabela 3). Verifica-se que nas profundidades de 8 e $10 \mathrm{~cm}$, uma maior população (respectivamente de 218333 plantas ha ${ }^{-1}$ e 209630 plantas ha $^{-1}$ ) e produção de palha de soja (respectivamente de $4131 \mathrm{~kg} \mathrm{ha}^{-1}$ e $4055 \mathrm{~kg} \mathrm{ha}^{-1}$ ). Nessas profundidades obteve-se maior produção de palha total do cultivo anterior (Tabela 1).

A variação na população de plantas de soja, decorrente dos consórcios utilizados no milho anteriormente não influenciou na produtividade de grãos de soja (Tabela 3). Segundo Peixoto et al. (2000) os caracteres componentes da produção apresentam variações entre eles, com efeito de compensação no sentido de uniformizar a produtividade de grãos, entre

Cultura Agronômica, Ilha Solteira, v.26, n.3, p.225-236, 2017 
cultivares, densidades e época de semeadura, sendo a época de semeadura o fator que mais influencia na produtividade de grãos.

Na Tabela 3, contata-se que a produtividade de grãos de soja não foi significativamente influenciada pela palha dos consórcios e tão pouco pelas profundidades de deposição de adubo e sementes das forrageiras. Garcia (2012) também não constatou efeito das palhadas de forrageiras do gênero Urochloa + milho de verão sobre a produtividade de grãos de soja. Entretanto, Kluthcouski et al. (2003), estudando o efeito das palhadas de arroz e U.brizantha sobre a produtividade de grãos de soja, constataram melhores resultados de produtividade sobre palhada de $U$. brizantha. Chioderoli (2010) verificou que palhada propiciada pelo cultivo de consórcio de milho outonal com diferentes espécies forrageiras ( $U$. brizantha, $U$. decumbens e $U$. ruzizienses) não influenciaram na produtividade da soja.

Tabela 3. Valores de F, coeficientes de variação e valores médios de população final, produtividade de grãos e de matéria seca de palha de soja sobre palha de milho outonal consorciado com duas espécies de forrageiras semeadas em diferentes profundidades. (Selvíria/MS, 2009/10).

\begin{tabular}{|c|c|c|c|c|}
\hline & & $\begin{array}{l}\text { População } \\
\quad \text { final } \\
\left(\text { Plantas ha-1) }^{-1}\right.\end{array}$ & $\begin{array}{l}\text { Matéria seca de } \\
\text { palha de soja } \\
\quad\left(\mathrm{kg} \mathrm{ha}^{-1}\right)\end{array}$ & $\begin{array}{l}\text { Produtividade de } \\
\text { grãos } \\
\left(\text { kg ha }^{-1}\right)\end{array}$ \\
\hline \multirow{3}{*}{$\begin{array}{l}\text { Sistemas de } \\
\text { cultivo } \\
(\mathbf{S})\end{array}$} & ME & $206111 \mathrm{a}$ & $3902 \mathrm{a}$ & $3630 \mathrm{a}$ \\
\hline & MUb & $207037 \mathrm{a}$ & 3995 a & $3657 \mathrm{a}$ \\
\hline & MUr & $199815 \mathrm{a}$ & $3548 \mathrm{a}$ & 3949 a \\
\hline \multirow{3}{*}{$\begin{array}{l}\text { Profundidades } \\
\text { de semeadura } \\
\text { (P) }\end{array}$} & $8 \mathrm{~cm}$ & $218333 \mathrm{a}$ & $4131 \mathrm{a}$ & $3666 \mathrm{a}$ \\
\hline & $10 \mathrm{~cm}$ & $209630 \mathrm{ab}$ & $4055 \mathrm{a}$ & $3857 \mathrm{a}$ \\
\hline & $16 \mathrm{~cm}$ & $185000 \mathrm{~b}$ & $3259 \mathrm{~b}$ & $3713 \mathrm{a}$ \\
\hline \multirow{3}{*}{ Valor de F } & $\mathbf{F}$ & $0,184^{\mathrm{ns}}$ & $1,965^{\mathrm{ns}}$ & $1,107^{\mathrm{ns}}$ \\
\hline & $\mathbf{P}$ & $3,554^{*}$ & $8,263 * *$ & $0,353^{\mathrm{ns}}$ \\
\hline & $\mathbf{F} \times \mathbf{P}$ & $1,592^{\mathrm{ns}}$ & $0,735^{\mathrm{ns}}$ & $1,909^{\mathrm{ns}}$ \\
\hline \multicolumn{2}{|l|}{ D.M.S. (5\%) } & 32401 & 594 & 594 \\
\hline \multicolumn{2}{|l|}{ C.V. (\%) } & 15,55 & 15,26 & 15,54 \\
\hline \multicolumn{2}{|l|}{ Média Geral } & 204321 & 3815 & 3745 \\
\hline \multicolumn{5}{|c|}{$\begin{array}{l}\text { **significativo } \mathrm{p}<0,01 \quad \text { *significativo } 0,01<\mathrm{p}<0,05 \quad \text { ns: } \text { não significativo } \\
\text { Médias seguidas de mesma letra na coluna não diferem pelo teste de Tukey, a } 5 \% \text { de probabilidade. } \\
\mathrm{ME}=\text { Milho Exclusivo, } \mathrm{MUb}=\text { Milho }+ \text { U.brizantha e } \mathrm{MUr}=\text { Milho }+ \text { U.ruziziensis }\end{array}$} \\
\hline \multicolumn{5}{|c|}{$\begin{array}{l}\text { A produtividade média de grãos de soja foi de } 3745 \mathrm{~kg} \mathrm{ha}^{-1} \text { sendo, portanto, superior a } \\
\text { produtividade média da soja brasileira que é de } 2941 \mathrm{~kg} \mathrm{ha}^{-1} \text {, segundo dados da Embrapa } \\
\text { Soja (2012). Pitol et al. (2001) obtiveram produtividade de soja sob palhada de braquiárias } \\
\text { (U.decumbens e U.brizantha) em solos anteriormente cobertos por pastagens degradadas } \\
\text { variando de } 2404 \mathrm{~kg} \mathrm{ha}^{-1} \text { a } 3468 \mathrm{~kg} \mathrm{ha}^{-1} \text {, portanto abaixo às obtidas no presente trabalho. O } \\
\text { bom desempenho da soja em área coberta por Urochloa, de acordo com Salton (2000) pode }\end{array}$} \\
\hline
\end{tabular}

Cultura Agronômica, Ilha Solteira, v.26, n.3, p.225-236, 2017 
ser devido, dentre outros fatores ao melhor enraizamento da planta e a redução de fontes de inóculos de doenças como o Mofo-branco.

\section{CONCLUSÃO}

No consórcio de milho com braquiárias na linha de semeadura as maiores produções de palha foram verificadas nos tratamentos com profundidades de deposição de sementes das forrageiras de 8 e $10 \mathrm{~cm}$. No tratamento onde a deposição de sementes das braquiárias se deu na profundidade de $16 \mathrm{~cm}$, a produção de palha da forrageira foi muito inferior aos demais tratamentos.

O total de palha obtido nas menores profundidades de semeadura das forrageiras em consórcio com milho proporcionou, na cultura da soja, maior produção de palha e população de plantas, porém não influenciou na produtividade de grãos de soja.

\section{REFERÊNCIAS BIBLIOGRÁFICAS}

AMADO, T. J. Manejo da palha, dinâmica da matéria orgânica e ciclagem de nutrientes em plantio direto. In: ENCONTRO NACIONAL DE PLANTIO DIRETO NA PALHA, 7., 2000, Foz do Iguaçu. Anais... Foz do Iguaçu: FBPDP, 2000. p. 105-111.

BONETTI, L. P. Cultivares e seu melhoramento genético. In: VERNETTI, F. J., (ed.) Soja: genética e melhoramento. Campinas: Fundação Cargill, 1983. p. 741-794.

BROCH, D. L.; CECCON, G. Produção de milho safrinha com integração lavoura-pecuária. In: SEMINÁRIO NACIONAL DE MILHO SAFRINHA, 9., 2007, Dourados. Anais... Dourados: Embrapa Agropecuária Oeste, 2007. p.121-128.

BROCH, D. L.; RANNO, S. K. Fertilidade do solo na cultura da soja. In: Tecnologia de produção de soja 2007/2008. Maracaju: Fundação MS para Pesquisa e Difusão de Tecnologias Agropecuárias, 2007. p.7-37.

CHIODEROLI, C. A. Consorciação de braquiárias com milho outonal em sistema plantio direto como cultura antecessora da soja de verão na integração agriculturapecuária. 2010. 82 f. Dissertação (Mestrado em Agronomia) - Faculdade de Engenharia, Universidade Estadual Paulista, Ilha Solteira, 2010.

CHIODEROLI, C. A.; MELlO, L. M. M.; GRIGOLli, P. J.; SILVA, J. O. R.; CESARIN, A. L. Consorciação de braquiárias com milho outonal em plantio direto sob pivô central. Engenharia Agrícola, Jaboticabal, v. 30, n. 6, p.1101-1109, 2010. Disponível em: http://www.scielo.br/pdf/eagri/v30n6/a11v30n6.pdf. Acesso em: 27 abr. 2017.

COSTA, J. A. A.; KICHEL, A. N.; ALMEIDA, R. G.; ZIMMER, A. H. Produtividade de soja semeada em palhada de capins cultivados em consórcio com milho na safrinha. In: CONGRESSO NACIONAL DE MILHO E SORGO, 28., 2010, Goiânia. Anais... Goiânia: Associação Brasileira de Milho e Sorgo. CD-ROM.

Cultura Agronômica, Ilha Solteira, v.26, n.3, p.225-236, 2017 
COSTA, N. R.; ANDREOTTI, M.; ULIAN, N. A.; COSTA, B. S.; PARIZ, C. M.; CAVASANO, F. A; TEIXEIRA FILHO, M. C. M. Produtividade da soja sobre palhada de forrageiras semeadas em diferentes épocas e alterações químicas no solo. Revista Brasileira de Ciências Agrárias, Recife, v. 10, n. 1, p.8-16, 2015. Disponível em: http://www.agraria.pro.br/sistema/index.php?journal=agraria\&page=article\&op=view\&path \%5B\%5D=agraria_v10i1a3842\&path\%5B\%5D=1725. Acesso em: 27 abr. 2017.

EMPRESA BRASILEIRA DE PESQUISA AGROPECUÁRIA - Embrapa. Centro Nacional de Pesquisa de Solos. Sistema brasileiro de classificação de solos. 3. ed. Brasília: Embrapa, 2013. 353 p.

EMBRAPA SOJA. EMPRESA BRASILEIRA DE PESQUISA AGROPECUÁRIA. A soja. Disponível em: http://www.cnpso.embrapa.br/index.php?op_page=22\&. Acesso em: 23 abr. 2012.

FERNANDEZ, A. T.; TORRES, J. L. R.; PEREIRA, M. G.; FABIAN; A. J. Decomposição dos resíduos culturais de milho e soja sobre diferentes coberturas de solo numa área sob semeadura no cerrado. In: SEMINÁRIO DE INICIAÇÃO CIENTÍFICA DO CEFET, 1., 2008, Uberaba. Anais... Uberaba: CEFET. Disponível em: http://www.iftm.edu.br/proreitorias/pesquisa/revista/index.htm. Acesso em: 24 fev. 2011.

FERREIRA, D.F. SISVAR: um programa para análises e ensino de estatística. Revista Symposium, Lavras, v. 6, n. 2, p.36-41, 2008.

GARCIA, C. M. P. Produtividade do milho e de matéria seca de forrageiras em consórcio e doses de nitrogênio na cultura da soja em sucessão. 2012. 188 f. Dissertação (Mestrado em Agronomia) - Faculdade de Engenharia, Universidade Estadual Paulista, Ilha Solteira, 2012.

KLUTHCOUSKI, J.; STONE, L. F.; AIDAR, H. Integração lavoura-pecuária. Santo Antonio de Goiás: Embrapa Arroz e Feijão, 2003. 570 p.

MELLO, L. M. M. Efeitos de diferentes sistemas de preparo do solo na cultura da soja (Glycine max (L) Merrill) e sobre algumas propriedades de um Latossolo Vermelho Escuro de Cerrado. 1988. 132 f. Tese (Doutorado em Agronomia) - Faculdade de Ciências Agronômicas, Universidade Estadual Paulista, Botucatu, 1988.

MELLO, L. M. M. Integração agricultura-pecuária em plantio direto: atributos físicos do solo, produção de forragem, cobertura residual do solo e desempenho econômico. 2001. 72 f. Tese (Tese de livre docente) - Faculdade de Engenharia, Universidade Estadual Paulista, Ilha Solteira, 2001.

MOTA, T. M. Tratamento de sementes com inseticidas, mistura com fertilizantes e profundidades de semeadura na emergência e crescimento de braquiária. 2008. $63 \mathrm{f}$. Dissertação (Mestrado em Agronomia) - Universidade Federal de Viçosa, Viçosa, 2008.

PACHECO, L. P.; PIRES, F. R.; MONTEIRO, F. P.; PROCÓPIO, S. O.; ASSIS, R. L.; PETTER, F. A. Profundidade de semeadura e crescimento inicial de espécies forrageiras Cultura Agronômica, Ilha Solteira, v.26, n.3, p.225-236, 2017 
utilizadas para cobertura do solo. Ciência e Agrotecnologia, Lavras, v. 34, n. 5, p.12111218, 2010.

PANTANO, A. C. Semeadura de braquiária em consorciação com o milho em diferentes espaçamentos na integração agricultura-pecuária em plantio direto. 2003. 60 f. Dissertação (Mestrado em Agronomia) - Faculdade de Engenharia, Universidade Estadual Paulista, Ilha Solteira, 2003.

PARIZ, C. M.; ANDREOTTI, M.; AZENHA, M. V.; BERGAMASCHINE, A. F.; MELLO, L. M. M.; LIMA, R. C. Produtividade de grãos de milho e massa seca de braquiárias em consórcio no sistema de integração lavoura-pecuária. Ciência Rural, Santa Maria, v. 41, n. 5, p.875-882, 2011.

PEIXOTO, C. P.; CÂMARA, M. S.; MARTINS, M. C.; MARCHIORI, L. F. S.; GUERZONI, R. A.; MATTIAZZI, P. Épocas de semeadura e densidade de plantas de soja: I. Componentes da produção e rendimento de grãos. Scientia Agricola, Piracicaba, v. 57, n. 1, p.89-96, 2000.

PITOL, C.; GOMES, E. L.; ERBES, E. I. Avaliação de cultivares de soja em plantio direto sobre brachiárias. In: Resultados de pesquisa e experimentação: safra 2000/2001. Maracaju: Fundação MS para Pesquisa e Difusão de Tecnologias Agropecuárias, 2001. p. $40-48$.

PORTES, T. A.; CARVALHO, S. I. C.; OLIVEIRA, I. P.; KLUTHCOUSKI, J. Análise do crescimento de uma cultivar de braquiária em cultivo solteiro e consorciado com cereais. Pesquisa Agropecuária Brasileira, Brasília, v. 35, n. 7, p.1349-1358, 2000.

RAIJ, B. van.; ANDRADE, J. C.; CANTARELLA, H.; QUAGGIO, J. A. Análise química para avaliação da fertilidade de solos tropicais. Campinas: IAC, 2001. 285 p.

REZENDE, A. V.; VILELA, H. H.; ALMEIDA, G. B. S.; LANDGRAF, P. R. C.; ANDRADE, G. A.; VIEIRA, P. F. Germinação de Sementes de forrageiras em diferentes profundidades de semeadura. In: CONGRESSO DE FORRAGICULTURA E PASTAGENS, 2., 2007, Lavras. Anais... Lavras: NEFOR, 2007. 1 CD-ROM.

SALTON, J. C. Opções de safrinha para agregação de renda nos cerrados. In: ENCONTRO REGIONAL DE PLANTIO DIRETO NO CERRADO, 4, 2000, Uberlândia. Anais... Uberlândia: UFU, 1999. v. 1. p. 189-200.

TRECENTI, R. Técnicas de consórcio ajudam na formação de palha para o plantio direto. Revista Plantio Direto, Passo Fundo, v. 86, n. 2, s/p., 2005. Disponível em: <http://www.plantiodireto.com.br/?body=cont_int\&id=616>. Acesso em: 04 dez. 2009.

Cultura Agronômica, Ilha Solteira, v.26, n.3, p.225-236, 2017 